\title{
A EaD no Brasil e o Processo de Democratização do Acesso ao Ensino Superior: Diálogos Possíveis
}

\author{
Felipe Augusto Fernandes Borges ${ }^{1}$
}

\begin{abstract}
1 Mestre em Educação, licenciado em Pedagogia e Tutor a distância na Universidade Estadual de Maringá. Pedagogo da Universidade Federal do Paraná - Campus Avançado de Jandaia do Sul. Rua Dr. João Maximiano, 426, Vila Operária- Jandaia do Sul- PR - Brasil. felipeborges@ufpr.br
\end{abstract}

\section{Resumo}

A utilização da EaD como forma de democratizar o ensino superior no Brasil tem sido discutida por pesquisadores afetos aos mais diversos temas educacionais. Trazemos neste estudo uma breve retomada histórica, demonstrando que os primeiros cursos de ensino superior no Brasil não se destinavam às consideradas classes subalternas. Esse processo histórico fez com que o ensino superior se tornasse algo quase restrito às classes dominantes. Apresentamos a EaD e sua legislação a fim de introduzir também a criação e implementação do Sistema Universidade Aberta do Brasil (UAB), política com vistas à democratização do acesso ao ensino superior. Elencamos alguns autores contrários ao uso da EaD como forma de democratizar o ensino no Brasil. Embora em direções diferentes, os autores contrários ao uso da EaD caminham quase sempre num mesmo viés. Um dos principais argumentos trazidos no bojo de suas argumentações contrárias é de que a EaD estaria servindo apenas aos interesses "mercantilistas" preconizados pela reestruturação do aparelho do Estado, operacionalizado principalmente na década de 1990. Tais autores desconsideram os avanços obtidos por meio da EaD, a despeito dos percalços e/ou dificuldades enfrentadas em tal modalidade. Sendo assim, trazemos autores favoráveis à implementação da EaD como política de popularização do ensino, a fim de demonstrar como ela tem sido importante no processo histórico de democratizar o ensino superior em nosso país, ampliando suas vagas, avançando na questão do acesso e, ainda, interiorizando as IES públicas e privadas em praticamente todo o território nacional.

Palavras-chave: EaD; Ensino a distância no Brasil; Democratização do ensino superior. 


\title{
The EaD in Brazil and the Process of Democratization of Access to Higher Education: Possible Dialogues
}

\begin{abstract}
The use of E-learning as a way to democratize higher education in Brazil has been discussed by researchers concerned about the most diverse educational themes. We bring in this study a brief historic overview showing that the first higher education courses in Brazil were not destined to the classes considered subaltern. This historical process has made higher education to become something almost restricted to the dominant classes. We present E-learning and its legislation in order to introduce also the creation and implementation of Open University System of Brazil (UAB), with aiming the access to higher education democratization. We also mention some authors opposed to use of E-learning as a way to democratize the education in Brazil. Although in different directions, authors opposed to use of E-learning follow the same bias almost always. One of the main arguments is that E-learning was only serving the "mercantilist" interests recommended by the State reconstruction process which took place mainly in the 90s. Such authors disregard the advances obtained by education through E-learning, despite the difficulties faced in such modality. Therefore, we bring authors in favor of E-learning as education democratization policy implementation in order to demonstrate how $\mathrm{E}$ learning has been important in the historical process higher education democratization in our country, increasing their number of vacancies, improving the issue of access and interiorizing the public and private Institutions of Higher Education in almost all the national territory.
\end{abstract}

Keywords: E-learning; Distance education in Brazil; Higher education; Democratization. 


\section{Introdução}

A utilização e o emprego da EaD como forma de democratizar (ou não) o ensino superior no Brasil têm sido assuntos amplamente discutidos por pesquisadores afetos aos mais diversos temas educacionais. Argumentos não faltam às duas partes.

Alguns autores defendem a EaD como uma modalidade de ensino capaz de ampliar o número e as possibilidades de acesso ao ensino superior a parcelas cada vez maiores da população (Alonso, 2010; Costa, 2008; 2009; 2012; Santos, \& Cerqueira, 2009; Vianney, 2003). Assim, segundo esses, os programas governamentais de apoio e fomento à criação e implementação de cursos superiores via EaD contribuem, significativamente, para que o nível superior da educação seja cada vez mais acessível em nosso país.

Contrariamente, outro grupo de autores denuncia um suposto esvaziamento de conteúdos, como uma forma de redução na qualidade de ensino e de formação crítica, segundo eles, operacionalizados por meios dos cursos de EaD. Dessa forma, julgam as políticas de fomento a essa modalidade de ensino como puramente interessadas numa (também suposta) "mercantilização" do ensino, tudo isso orquestrado pelas diretrizes trazidas pelo conjunto dos organismos internacionais/multilaterais envolvidos com as políticas brasileiras.

Nesse sentido, o presente artigo caminha na direção de, inicialmente, contextualizar o ensino superior no Brasil, tendo em vista um pouco de sua história e alguns números mais atualizados sobre seus níveis de acesso e conclusões. $\mathrm{Na}$ sequência, discutiremos a historicidade da EaD no Brasil, seu envolvimento com programas para o ensino superior e sua legislação atual, principalmente no que tange à sua presença na LDB 9.394/96.

Depois de contextualizados esses processos, traremos alguns argumentos contrários e outros favoráveis ao uso da EaD para a expansão e democratização do acesso ao ensino superior no Brasil, para, por fim, nos posicionarmos também favoravelmente a essa modalidade.

Concluiremos, no fim deste estudo, que a EaD, a despeito de quaisquer argumentos ou críticas, tem sido uma eficaz forma de democratizar o acesso ao ensino superior, sendo isso demonstrado por meio de estatísticas comprovadas. 


\section{Ensino Superior no Brasil}

A historicidade do ensino superior no Brasil obedece, obviamente, à lógica da colonização que aqui se implantou. Como colônia de Portugal, as decisões a respeito de cursos, escolas e quaisquer demais temas importantes no Brasil estavam, até a independência, submissas aos ditames da Coroa Portuguesa.

Dessa forma, enquanto apenas colônia sob a autoridade da metrópole, não há no Brasil registros da criação ou implantação de cursos superiores. A elite social, que aqui poderia iniciar seus estudos, sobretudo sob a tutela da Igreja, acabava por ir à Europa e, lá sim, concluir seus estudos, principalmente nos cursos de Direito e Medicina (Santos, \& Cerqueira, 2009).

A situação da educação e da cultura no Brasil colonial sofrerá algumas mudanças apenas a partir de 1808, quando a Família Real, fugindo do cerco napoleônico, desembarca na colônia, elevando-a à condição de Reino Unido a Portugal. Com a vinda do então príncipe regente D. João VI e a respectiva Corte, há uma abertura nas questões educacionais e culturais e certo desenvolvimento para o que hoje chamamos de ensino superior.

Neste ano foram fundadas as escolas: a) de Cirurgia e Anatomia (mais tarde: Faculdade de Medicina da Universidade Federal da Bahia; b) de Anatomia e Cirurgia do Rio de Janeiro (posteriormente: Faculdade de Medicina da Universidade Federal do Rio de Janeiro) e c) Academia de Guarda da Marinha, também no Rio de Janeiro. (Santos, \& Cerqueira, 2009, p.16).

Como se pode notar, evidentemente, os primeiros cursos de ensino superior no Brasil nem mesmo de longe se destinavam às consideradas classes subalternas. O início do desenvolvimento desse nível de ensino no país já marca uma elitização, até porque, nesse período, apenas os filhos da elite tinham condições de deter os requisitos mínimos para ingresso na modalidade superior de ensino.

A descentralização do ensino superior e a possibilidade de criação de universidades propriamente ditas acontecem apenas com o advento da República. No período que se seguiu a essa nova estrutura de poder, o país assistiu a uma lenta e tímida expansão, impulsionada mais pela criação de instituições privadas do que por iniciativas públicas. Houve, dessa forma, a criação de instituições de ensino superior privadas, dentre as 
quais exerceram grande importância as de caráter confessional, com destaque para as confissões católicas e presbiterianas (Santos, \& Cerqueira, 2009).

O que se pode observar é que o caráter restrito e elitista do ensino superior tem se mantido quase intacto, desde a fase monárquica até a atualidade. Mais precisamente, as políticas públicas para aumento de vagas e consequente democratização do ensino superior só se tornaram mais evidentes a partir dos programas criados já no governo Lula (Santos, \& Cerqueira, 2009).

O estreito acesso ao ensino superior pode ser quantificado por meio de estatísticas. Segundo dados do último censo, apenas $11,3 \%$ da população brasileira entre 20 e 25 anos têm ensino superior completo (Leal, 2012). Na verdade, essa é uma estatística geral, tirando as diferenças entre as regiões brasileiras. Quando consideradas as diferentes regiões, as dificuldades de acesso ficam ainda mais latentes, pois:

Há um abismo no nível de instrução de adultos do Nordeste e do Sudeste, de acordo com os dados do Censo 2010. [...] na Região com os melhores resultados, os índices são preocupantes. Entre as pessoas com 25 anos ou mais do Sudeste, $13,7 \%$ têm curso superior completo. No Nordeste, são apenas 7,1\% (Leal, 2012).

Para demonstrar os números de forma mais concisa, trazemos abaixo um gráfico contendo o número de matrículas no ensino superior por ano, de 2001 a 2010, consideradas as modalidades presenciais e a distância.

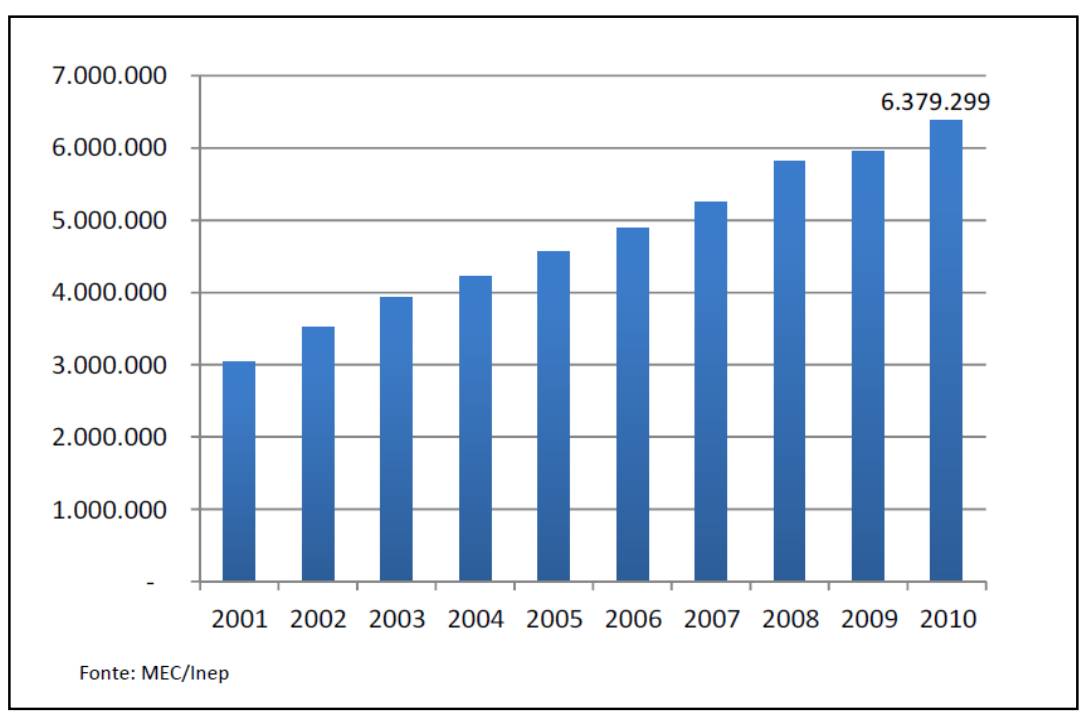

Gráfico 1: Número de matrículas no ensino superior por ano (2001-2010). Fonte: IBGE, 2011. 
Considerando o número de matrículas (acesso) no ano de 2010, precisamos então compará-lo ao número total da população brasileira: 190.732.694 (IBGE, 2011). Tal comparação nos mostra que ainda é restrito e pequeno o percentual de acesso ao nível superior. Vale ressaltar que aqui apresentamos o número de matrículas, o que não reflete, necessariamente, as conclusões do referido nível de ensino. O número de conclusões pode ser visto no gráfico abaixo:

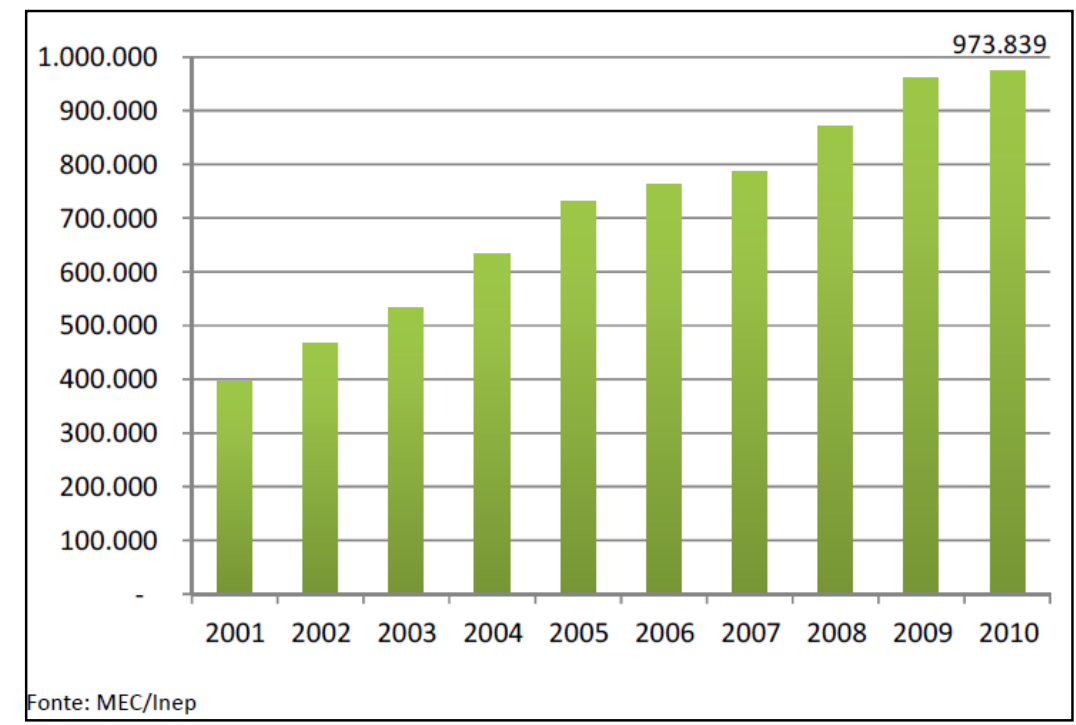

Gráfico 2: Número de conclusões no ensino superior por ano (2001-2010). Fonte: IBGE, 2011.

Quando analisada pormenorizadamente, e em comparação com os números da população total do país, a quantidade de pessoas que se formam em cursos de graduação reafirma a restrição não somente do acesso, mas ainda da permanência e conclusão no ensino superior.

Ainda que brevemente, procuramos, neste tópico, apresentar essa deficiência como resultado de um processo histórico, de início restrito e que, nos últimos anos, vem sendo lentamente ampliado. Uma das formas de gerenciar tal ampliação de acesso e democratização tem sido a modalidade EaD em ensino superior. É nesse sentido que o presente trabalho prossegue sua análise. 


\section{EaD no Brasil}

A EaD tem sido há muito tratada com status de "novidade" ou "inovação" no cenário educacional brasileiro. Muitos, de forma leiga, têm se referido a tal modalidade de ensino como se fosse algo recém-criado, sem uma fundamentação teórica ou mesmo uma organização que lhe dê suporte. Quando envolvidos/embasados na teoria e na historicidade da modalidade EaD no Brasil, podemos observar que tal visão simplista é, também, errônea.

Teóricos da EaD divergem quando instados a apontar o que seria o marco inicial dos programas dessa modalidade de ensino em nosso país (e mesmo no mundo). Há aqueles que, como Vianney (2003), defendem que o início da EaD no Brasil demarca-se já no ano de 1904. Afirma-se isso com base em anúncios de cursos a distância (pagos), presentes em jornais do Rio de Janeiro (Costa, 2008).

Entretanto, cabe-nos aqui ressaltar que outros autores, tais como Saraiva (1996 apud Costa, 2008) e Costa (2012), consideram que a EaD no Brasil tem real aplicação a partir de 1923, por meio da criação da Rádio Sociedade do Rio de Janeiro, por Edgar Roquette-Pinto. Esse processo tinha como finalidade ampliar o acesso à educação por meio da radiodifusão, portanto, apontam os autores, seria uma primeira forma de levar um conteúdo educacional à população por meios não presenciais.

Depois da iniciativa de Roquette-Pinto, temos, no final da década de 30, já início da de 40 do século XX, a presença de instituições como o Instituto Universal Brasileiro, o Instituto Rádio Monitor e outros, que também representam um pioneirismo nos cursos EaD no país (Costa, 2008). Instituições como o Instituto Universal ofereciam cursos dos mais diversos: desde as famosas aulas de corte e costura, até as de datilografia e, posteriormente, os cursos profissionalizantes, como eletrônica e afins. Vale aqui sublinhar que, apesar de pioneiros, esses cursos não possuíam nenhum tipo de avaliação ou monitoramento por parte dos órgãos educacionais. Eram modelos de cursos livres, com apostilas, K7s, VHSs e quaisquer outros meios de intermediações "virtuais" possíveis à época de cada um deles.

Com relação à oficialização da EaD no país, segundo a perspectiva de Saraiva (apud Costa, 2008, p.14):

[...] é a partir da década de 1960 que se encontram registros, alguns sem avaliação, de programas de EaD desenvolvidos no Brasil. Nessa época, foi 
criado, na estrutura do Ministério da Educação e Cultura (MEC), o Programa Nacional de Teleducação (Prontel), a quem competia coordenar e apoiar a teleducação no Brasil. Este órgão foi substituído, anos depois, pela Secretaria de Aplicação Tecnológica (Seat), extinta posteriormente. Em 1992, foi criada a Coordenadoria Nacional de Educação a Distância na estrutura do MEC, e, a partir de 1995, a Secretaria de Educação a Distância ${ }^{1}[\ldots]$.

Vemos, no excerto acima, que, a partir da década de 1960, já há no Brasil um esforço oficial pela implementação de projetos de $\mathrm{EaD}$ por parte dos próprios órgãos governamentais. Esse ideário é visível mais claramente quando, na década de 70, mais precisamente em 1972, o Congresso Nacional recebe a primeira proposta (projeto de lei) de criação da Universidade Aberta. Em 1987, esse projeto é reapresentado, não obtendo sucesso em nenhuma das vezes citadas (Costa, 2012).

Embora o projeto de lei de 1972 não tenha obtido sucesso em suas primeiras apresentações, observamos que o ideário da $\mathrm{EaD}$ já estava presente em programas governamentais como o Projeto Minerva. Esse projeto pretendia interiorizar a educação básica por meio da radiodifusão, como forma de auxiliar o país no combate aos altos índices de analfabetismo presentes até então.

Autores como Peixe (2003, apud Costa, 2008) e Alonso (2003, apud Costa) apontam para o fato de que, principalmente no período do governo militar, os projetos de EaD sofriam de certa pressão externa, considerados como soluções rápidas para problemas históricos advindos da situação econômica e social do país. Segundo eles, esses primeiros projetos ocorrem num momento de certo crescimento econômico, quando a educação era vista como motor para criação de mão de obra para os mercados que se abriam.

Outro problema nos primeiros projetos de EaD no país é apontado por Nunes (2003): a descontinuidade. Segundo o autor, citado por Costa (2008), projetos como Minerva e MEB (Movimento de Educação de Base) sofreram de mudanças e descontinuidades, o que atrapalhou o total sucesso de suas implementações.

Analisando o cenário e as legislações educacionais no Brasil e, ainda, apoiados em autores que estudam o assunto, podemos afirmar que a primeira legitimação oficial da EaD no país se dá por meio da Lei de Diretrizes e Bases da Educação Nacional de 1996 (LDB 9.394/96). Na referida lei, temos um conjunto de artigos que abrem caminho a uma legitimação de programas que, posteriormente, vieram a impulsionar a EaD 
brasileira, dando espaço, por exemplo, ao Sistema da Universidade Aberta do Brasil (UAB), que será referido posteriormente em nosso trabalho.

Na LDB, há um conjunto de dispositivos que remetem à EaD, como demonstrado no quadro abaixo.

Quadro 1: Artigos, parágrafos e incisos da LDB referentes à EaD.

\begin{tabular}{|c|c|c|c|}
\hline Artigo & $\S$ & Inciso & Descrição \\
\hline Art. 32 & $\S 4^{\circ}$ & & $\begin{array}{l}\text { O ensino fundamental será presencial, sendo o ensino a distância } \\
\text { utilizado como complementação da aprendizagem ou em } \\
\text { situações emergenciais. }\end{array}$ \\
\hline Art. 46 & $\S 30$ & & $\begin{array}{l}\text { É obrigatória a frequência de alunos e professores, salvo nos } \\
\text { programas de educação a distância. }\end{array}$ \\
\hline \multirow[t]{8}{*}{ Art. 80} & & & $\begin{array}{l}\text { O Poder Público incentivará o desenvolvimento e a veiculação de } \\
\text { programas de ensino a distância, em todos os níveis e } \\
\text { modalidades de ensino, e de educação continuada. }\end{array}$ \\
\hline & $\S 10$ & & $\begin{array}{l}\text { A educação a distância, organizada com abertura e regime } \\
\text { especiais, será oferecida por instituições especificamente } \\
\text { credenciadas pela União. }\end{array}$ \\
\hline & $\S 20$ & & $\begin{array}{l}\text { A União regulamentará os requisitos para a realização de } \\
\text { exames e registro de diploma relativos a cursos de educação a } \\
\text { distância. }\end{array}$ \\
\hline & $\S 30$ & & $\begin{array}{l}\text { As normas para produção, controle e avaliação de programas de } \\
\text { educação a distância, e a autorização para sua implementação } \\
\text { caberão aos respectivos sistemas de ensino, podendo haver } \\
\text { cooperação e integração entre os diferentes sistemas. }\end{array}$ \\
\hline & $\S 4^{\circ}$ & & $\begin{array}{l}\text { A educação a distância gozará de tratamento diferenciado, que } \\
\text { incluirá: }\end{array}$ \\
\hline & & I- & $\begin{array}{l}\text { custos de transmissão reduzidos em canais comerciais de } \\
\text { radiodifusão sonora e de sons e imagens; }\end{array}$ \\
\hline & & II- & concessão de canais com finalidades exclusivamente educativas; \\
\hline & & III- & $\begin{array}{l}\text { reserva de tempo mínimo, sem ônus para o Poder Público, pelos } \\
\text { concessionários de canais comerciais. }\end{array}$ \\
\hline
\end{tabular}

Fonte: Santinello, 2009, p32-33.

Como demonstrado pelo Quadro 1, a LDB trata da EaD em aspectos mais gerais. A pormenorização dos aspectos relacionados ao artigo 80 da LDB dar-se-á por meio do decreto $n^{\circ} 5.622$ de 19 de dezembro de 2005, que, até o presente momento, é ainda a legislação que regulamenta a oferta de cursos EaD no país. 
Fizemos essa breve localização da EaD no tempo e na legislação brasileiras a fim de introduzir aqui a criação e implementação do Sistema Universidade Aberta do Brasil (UAB), já supracitada neste trabalho.

O sistema UAB não se configura como uma instituição de ensino, porém constituise numa rede de instituições públicas de ensino superior articuladas para a oferta de cursos superiores (de graduação e pós-graduação) na modalidade EaD. Essa rede conta, hoje, com um grande número de polos presenciais, professores e tutores, e tem como um de seus objetivos principais a formação inicial e continuada de docentes para os ensinos fundamental e médio (Santinello, 2009). Segundo Costa (2009, p.24),

\begin{abstract}
A expressão Sistema Universidade Aberta do Brasil é a denominação representativa genérica para a rede nacional experimental voltada para a pesquisa e para a educação superior formada pelo conjunto de instituições públicas de ensino superior, em articulação e integração com o conjunto dos polos municipais de apoio presencial. Não se trata, portanto, da criação de uma nova instituição educacional, mas sim da constituição de consórcios públicos que propiciem o compartilhamento das experiências isoladas, sejam elas marcadas pelo êxito ou então na socialização das dificuldades enfrentadas.
\end{abstract}

Como vemos, o Sistema UAB é uma ação, no âmbito das políticas públicas para EaD no Brasil, com vistas a interiorizar e democratizar a educação superior no país. Tal aspecto será tratado na sequência deste trabalho. Neste momento, desejamos apenas destacar o caráter histórico de desenvolvimento de tais políticas no Brasil, que, grosso modo, têm como pano de fundo a necessidade de expansão de um já demonstrado tão restrito ensino superior.

Destarte, a EaD vem tomando força no cenário da educação nacional, ganhando espaço e comprovando, por meio de estatísticas, sua eficiência tanto qualitativa quanto quantitativamente no processo de aumento de vagas e democratização do ensino superior.

\title{
4. EaD no Processo de Democratização do Ensino Superior
}

Apresentamos, até o momento, alguns aspectos da historicidade do ensino superior de forma geral e também da modalidade de EaD no Brasil. Com tal apresentação, pretendemos demonstrar, inicialmente, as condições de acesso e permanência no ensino superior brasileiro, bem como apontar os programas de EaD 
como uma possibilidade da ampliação do número de vagas e consequente democratização do acesso a esse nível de ensino, principalmente na esfera pública.

Porém, queremos, neste momento, trazer mais detalhadamente essa discussão, considerando que, ao mesmo tempo em que uma gama de autores e estudiosos defende a utilização da modalidade EaD como forma de ampliação do acesso ao nível superior, existe outra vertente formada por vorazes críticos da modalidade. Tais críticas englobam desde as relações com os organismos internacionais ${ }^{2}$ em face da reestruturação neoliberal do Estado, até as chamadas relações de "precarização" do trabalho docente via EaD, expressa, para tais autores, na figura do tutor (presencial ou não).

Elencamos aqui alguns autores que se posicionam contrários ao uso da EaD como forma de democratizar o ensino superior no Brasil. Na sequência, apresentaremos alguns dos argumentos de cada um deles. São eles: Malanchen (2007), Lima (2007; 2011), Pereira (2009) e Silva, Silva, Jimenez e Segundo (2012). Cada um desses autores apresenta argumentos contrários à EaD que devem, a nosso ver, ser considerados para reflexão.

Embora em direções diferentes, os autores contrários ao uso da EaD caminham quase sempre num mesmo viés. Um dos principais argumentos trazidos no bojo de suas argumentações contrárias é que a EaD estaria servindo apenas aos interesses "mercantilistas" preconizados pela reestruturação do aparelho do Estado, operacionalizada principalmente na década de 1990. Vejamos abaixo a afirmação de Malanchen:

[...] concluímos que o interesse na democratização do acesso à educação, além de criar uma ilusão de que todos, por meio dela, podem melhorar suas vidas, carrega outra intenção: a de formar mão de obra especializada para a nova fase de acumulação do capital que exige trabalhadores capacitados tecnicamente, criativos, eficientes e adaptáveis. [...] isso também ocorre por meio da EaD, que tem nas Tecnologias da Informação e Comunicação sua melhor forma de operacionalização. Em outros termos, a educação passa a ser vista como um instrumento para o desenvolvimento econômico, para o ajustamento dos indivíduos ao chamado mercado de trabalho, deixando-se em segundo plano a questão da educação como instrumento de emancipação humana [...]. (Malanchen, 2007, p.211).

Por meio dos argumentos anteriores é que a autora se refere à EaD como um "canto da sereia", sendo que essa expressão é inclusive trazida no título de seu artigo. Mais incisivamente, ela afirma, adiante, que 
[...] as políticas de EaD, justificadas como uma forma de democratizar o acesso à educação, colocadas em prática de forma mais incisiva na formação docente, têm como intenção a desintelectualização docente. A formação docente a distância é, na verdade, mais uma das estratégias que, desde os anos de 1990, são postas em prática para despolitizar e controlar o professor. Outras estratégias, que comprovam nossa afirmação foram efetivadas, tais como: formação continuada por meio da TV Escola, Proformação, programas emergenciais de formação de professores em serviço (Projeto Veredas, Magister e Proformar) e a criação dos Institutos Superiores de Educação, assim como a abertura para que a iniciativa privada oferecesse formação de professores. (Malanchen, 2007, p.213).

Na sequência de seu trabalho, a autora continua na mesma linha de raciocínio, afirmando, no fim, que a EaD é apenas uma forma de consolidar os ideais do que ela chama de "democracia burguesa", e não do que considera uma verdadeira democracia intelectualizada, participativa e emancipadora.

Concordando com as afirmações de Malanchen (2007), trazemos o posicionamento de Lima, em dois artigos, nos quais faz duras críticas à EaD, também no sentido de relacionar essa modalidade a supostas imposições dos organismos internacionais. Em seu artigo "Educação a distância ou à distância da educação" (Lima, 2007), a autora caminha no sentido de que a EaD seria uma forma contraditória de inclusão social, pois, segundo ela, ao mesmo tempo em que se incluem aquilo que chama de "mais pauperizados da população" (p. 84) no ensino superior, as diretrizes dos organismos internacionais pressupõem a diversificação do investimento/financiamento da educação. Em outras palavras, enquanto se postula a inclusão da população nas universidades, a educação continuaria por se configurar num aparelho de movimentação neoliberal.

Em outro trabalho, Lima (2011) vai destacar que, para além de uma mera imposição de organismos internacionais, a utilização dos programas EaD para formação em nível superior (sobretudo formação de docentes) é chancelada pelos programas governamentais. Segundo ela, tais programas estariam no Brasil colaborando para o esvaziamento do sentido da educação, colocando a mesma como mercadoria lucrativa do mercado neoliberal. De acordo com a autora:

Cabe, entretanto, destacar que a liberalização dos serviços educacionais e a certificação em larga escala são políticas desses organismos internacionais, materializadas por meio das ações dos vários governos nos anos de neoliberalismo, de Fernando Henrique Cardoso a Luiz Inácio Lula da Silva. Não se trata, portanto, de algo imposto de fora para dentro ou de uma pretensa autonomia dos empresários do setor educacional ou dos 
reitores das universidades públicas, mas de um compartilhamento de concepções e de projetos, de políticas governamentais estabelecidas em parceria com esses organismos internacionais visando à lucratividade de burguesia de serviços educacionais (local e internacional) através da adequação da educação à nova fase de acumulação do capital. (Lima, 2011, p. 43, grifos da autora).

Caminhando na mesma direção das autoras supracitadas, há outro grupo que, para além de destacar a atuação dos organismos internacionais, traz especial destaque ao papel das Instituições de Ensino Superior (IES) privadas no processo de expansão da EaD. Para autores como Pereira (2009), a entrada das IES privadas principalmente no que tange à formação superior em EaD explicita a mercantilização da educação e, ainda, configura-se como uma possibilidade de escoamento de verbas públicas em direção a instituições privadas. Para dar ênfase à sua crítica, a autora cita programas de renúncia fiscal, como o ProUni, e aponta para o movimento de entrada das próprias IES públicas na lógica do mercado privado. Em suas palavras:

A década de 1990 e o início do século 21 registraram um franco processo
de expansão e de mercantilização do ensino superior, validado e
incentivado pelos governos, de Cardoso a Lula, pautados no pressuposto
de que a educação é um "bem público", sendo, portanto, um direito de
instituições públicas e privadas oferecerem seus serviços educacionais à
população. Cabe ao Estado a partilha dos recursos públicos: naturaliza-se
a entrega de verbas públicas para o setor privado e, ao mesmo tempo, o
financiamento privado para as IES públicas, numa explícita diluição de
fronteiras entre o público e o privado. (Pereira, 2009, p.271).

Vemos aqui que a crítica da autora não está diretamente relacionada à modalidade EaD em si, mas aos meios pelos quais ela é financiada. Pereira vincula a forma de financiamento e a abertura de possibilidades de investimento de verba pública nas IES privadas à chamada mercantilização do ensino, já discutida em excertos de outros autores neste trabalho.

A última vertente de críticas que abordaremos aqui diz respeito às formas de trabalho docente empregadas nos cursos da modalidade EaD. Para discorrer sobre o assunto, utilizaremos um relatório de pesquisa intitulado "Educação a distância e precarização do trabalho docente" (Silva et al., 2012), em que os autores discutem os resultados de uma investigação realizada no campo da EaD.

A gênese da crítica dos autores, sob nossa leitura, se encontra na forma de trabalho preconizada pela figura do tutor. Segundo Silva et al., o tutor serve como uma 
forma de reduzir custos na educação a distância, contribuindo para o incremento dos lucros advindos da mesma. Ainda nesse argumento, os autores afirmam a precarização do trabalho docente, na medida em que o tutor não tem status de professor, mas acaba, na dinâmica do processo, assumindo as funções relativas a este. Nesse sentido, Silva et al. apontam também para o empobrecimento da formação dos alunos de EaD justificados pela ausência de discussões mais aprofundadas, que deveriam ser fomentadas na figura do professor, e não do tutor.

A crítica se expande e atinge ainda o Sistema UAB, que, segundo os autores, acaba também por ampliar tal precarização por meio do recrutamento dos já referidos tutores. Pensamos ser importante recortar a afirmação abaixo, na qual os autores afirmam que, no momento,

\begin{abstract}
Vivencia-se, assim, o processo de expansão de cursos de formação de professores para educação básica, sem gerar, contudo, proporcionalmente, novos concursos públicos para a contratação de docentes para o magistério básico e superior público, diante da explícita substituição de professores na EaD por tutores, intensificando o processo de precarização, ao mesmo tempo, da formação e do trabalho dos professores. Vale ressaltar que a função do tutor não contempla qualquer relação trabalhista, uma vez que este faz jus tão somente a uma bolsa por suas atividades prestadas ao Fundo Nacional de Desenvolvimento da Educação (FNDE), sem mesmo qualquer vínculo com a instituição executora da UAB. (Silva et al., 2012, p. 228).
\end{abstract}

Como podemos observar, há várias críticas direcionadas à EaD, ao Sistema UAB, aos programas como ProUni e ainda a outros assuntos e temas relacionados à Educação a Distância. Nosso objetivo não foi, de maneira alguma, esgotar as críticas, mas apenas demonstrar em que direção (geral) elas apontam, a fim de estabelecer um diálogo entre visões favoráveis e contrárias a essa nova modalidade de ensino.

O que falta aos autores que criticam ferrenhamente a modalidade e os programas de EaD, a nosso ver, é considerar os avanços obtidos pela educação por meio desse novo recurso, a despeito dos percalços e/ou dificuldades enfrentadas por ele. Na sequência do trabalho, pretendemos apresentar os argumentos de autores em defesa da EaD e dos programas e ela relacionados. Com isso, pretendemos, ainda demonstrar que, apesar de possíveis dificuldades e/ou problemas (estes enfrentados por qualquer modalidade de ensino), a EaD tem cumprido muito bem seu papel no processo de expansão e democratização do acesso ao tão restrito ensino superior brasileiro. 
O problema do acesso ao ensino superior se deu, no Brasil, como já mencionado, por fatores históricos e sociais muito delimitados. Porém, nos últimos anos, pode-se perceber um gradativo aumento de vagas nas IES públicas, operacionalizadas pelo Sistema UAB, com a oferta de cursos sob a modalidade EaD. É evidente que muitas IES privadas também se utilizam da modalidade EaD para oferta de seus cursos. O que queremos ressaltar, no entanto, é que se torna frágil afirmar qualquer (des)qualidade dos referidos cursos apenas pautados na natureza de sua modalidade (EaD ou presencial).

Os cursos EaD, como quaisquer outros cursos de graduação presenciais, necessitam de avaliações periódicas, portarias, reconhecimentos e todas as outras exigências feitas às instituições, tanto públicas quanto privadas. Portanto, a questão da qualidade não deve ser discutida apenas com relação à modalidade $E a D$, mas em relação ao ensino como um todo. Se há deficiências qualitativas no ensino superior, elas não são advindas exclusivamente dos cursos EaD, mas são a soma dessas com as deficiências do próprio ensino presencial. A nosso ver, ao criticar a qualidade do ensino focando apenas na EaD, os autores estão apenas atenuando, em uma modalidade, uma deficiência histórica presente em todo um nível de ensino.

Devemos lembrar que o ensino por meio de EaD conta, atualmente, com uma grande gama de instrumentos que possibilitam a interação do aluno com o objeto da aprendizagem e, ainda, com professores, tutores e demais discentes. As Tecnologias de Informação e Comunicação (TICs) ${ }^{3}$ disponíveis presencialmente dão ao aluno todas as possibilidades de interação necessárias: acesso ao material digital (os cursos contam também com material impresso), vídeos, links de notícias e temas relacionados aos assuntos das disciplinas, salas de chat (bate-papo), onde os alunos podem se comunicar entre si, atendimento de professores e tutores e, ainda, muitas outras ferramentas. Para aqueles que defendem o pressuposto da "não interação" como deficiência do aluno de EaD, Ferreira (2008) mostra os argumentos anteriores e ainda outros, ao discorrer sobre os ambientes virtuais de aprendizagem (AVA).

Inegáveis são, ainda, os números que demonstram o crescimento do acesso ao ensino superior por meio da EaD no Brasil. Alonso (2010, p.1324) nos mostra alguns deles:

Se no ano de 2000 o INEP anunciava a existência de 10 cursos de graduação, em 2003 esse número era de 52, atendendo a cerca de 50 mil 
alunos. Em 19 de dezembro de 2006 o INEP noticiava que, entre os anos de 2003 a 2006, houve aumento de $571 \%$ de cursos a distância e de $371 \%$ dos matriculados nessa modalidade. Em 2005 os alunos da EaD representavam $2,6 \%$ do universo dos estudantes no nível superior. Já em 2006 essa participação fora aumentada para 4,4\%. Dados do Censo do Ensino Superior de 2007 indicaram que a graduação a distância era oferecida por 97 instituições, com o número de vagas aumentado em $89,4 \%$ em relação a 2006, totalizando 369.766 matrículas. Isto representava $7 \%$ do total de matriculas dos cursos de graduação. [...]

O Anuário Brasileiro Estatístico de EaD/2008 (ABRAD) estimou em 2.504.438 os brasileiros em cursos nesta modalidade. Destes, $40 \%$ cursavam graduação e $39 \%$ lato sensu. Os demais alunos estavam distribuídos em outros níveis de ensino.

Temos também que referenciar o fato de que as porcentagens acima descritas são de abertura de vagas interiorizando as instituições participantes tanto da UAB quanto dos sistemas privados. A instituição dos polos presenciais, necessários a qualquer curso EaD, contribui "como a estrutura necessária para a execução descentralizada de algumas das funções didático-administrativas do curso, rede ou sistema de educação a distância" (Costa, 2012, p. 28). Isso quer dizer que, na prática, uma estrutura administrativa das IES ofertantes de cursos EaD se interioriza, ou seja, vai para perto do aluno.

Na realidade, as próprias finalidades de criação do Sistema UAB delimitam em si o projeto de democratizar o ensino superior público. Em meio às finalidades do sistema, Costa e Zanatta (2008) destacam quatro, que são:

[...] (a) ampliar o acesso à educação superior pública; (b) reduzir as desigualdades de oferta de Ensino Superior entre as diferentes regiões do país; (c) estabelecer amplo sistema nacional de educação superior a distância; (d) fomentar o desenvolvimento institucional para a modalidade de educação a distância, bem como a pesquisa em metodologias inovadoras de Ensino Superior, apoiadas em tecnologias de informação e comunicação. (Costa, \& Zanatta, 2008, p.47).

Tendo em vista o exposto, afirmamos, mais uma vez, a possibilidade de alta qualidade nos cursos EaD, desde que sejam gerenciados de forma responsável e comprometida, numa dinâmica que privilegie a interação e participação de alunos, professores e tutores. A despeito das críticas, a EaD tem crescido nos últimos anos, os programas a ela relacionados e, principalmente, o Sistema UAB têm adquirido cada vez mais espaço dentro de renomadas IES públicas, tanto nas esferas estaduais quanto nas instituições federais. 
A presença de cursos EaD ofertados por instituições de já conhecido sucesso em cursos presenciais somente reforça o valor e a qualidade dos cursos a distância oferecidos pelas mesmas. Ainda, o Sistema UAB tem sido o motor de impulso que tem levado as IES públicas para os municípios mais interiorizados de seus estados, proporcionando o contato desses espaços com a cultura universitária e vice-versa.

A expansão no número de vagas ofertadas por meio dos cursos EaD também não pode ser ignorada. Não é possível negar que esse aumento de vagas causa também um incremento de possibilidades para as classes há muito excluídas das universidades. Assim, como já evidenciado, marcamos aqui nossa posição em favor dos cursos EaD, do Sistema UAB e de quaisquer demais programas que venham de alguma forma contribuir para a potencialização do ensino e democratização do acesso ao ensino superior em nosso país.

\section{Considerações Finais}

Como exposto em nosso trabalho, existem vários argumentos ligados aos processos de expansão da EaD no Brasil. As vertentes contrárias à modalidade se apoiam em discursos que enfatizam o papel dos organismos internacionais, do neoliberalismo e da reestruturação administrativa do Estado operadas principalmente na década de 1990.

Sem desmerecer os aplicados estudos de nossos pares, novamente destacamos o fato de que suas exposições desconsideram os avanços trazidos pela EaD, enumerando sistematicamente apenas os supostos problemas de implementação e gerenciamento da mesma. Além disso, tais estudos têm ultimamente se perguntado sobre a qualidade apenas dos cursos de EaD, relegando ao esquecimento as discussões de qualidade sobre o ensino presencial, ou ainda, sobre o ensino superior em sua totalidade. Com isso, os estudos críticos da EaD atribuem somente a elas essas deficiências e problemas, que, na verdade, pertencem a todo um sistema educacional.

Por fim, queremos deixar claro que nosso objetivo, por meio deste artigo, foi demonstrar como a EaD tem sido importante no processo histórico de democratizar o ensino superior em nosso país, substanciando suas vagas, avançando na questão do acesso e, ainda, interiorizando as IES públicas e privadas em praticamente todo o território nacional. 


\section{Notas}

${ }^{1}$ Cabe aqui destacar que a Secretaria de Educação a Distância, existente na estrutura do MEC à época em que o artigo citado foi escrito, já não mais existe, tendo sido extinta em 2012 sem explicações oficiais contundentes. A estrutura e o atendimento aos mais diversos programas de EaD foram, assim, "pulverizados" entre as demais secretarias do Ministério. O Sistema UAB, por sua vez, fica sob o organograma da Capes.

2 Referimo-nos, aqui, às organizações multilaterais, tais como ONU, Unesco, OCDE, Bird, FMI e outras.

3 Destacamos o uso das TICs em EaD, porém, ressaltamos que a utilização delas não está restrita à modalidade a distância, tendo também importante papel nas dinâmicas possíveis ao ensino presencial.

\section{Referências Bibliográficas}

Alonso, K. M. (2010). A expansão do ensino superior no Brasil e a EaD: dinâmicas e lugares. Educação e Sociedade,31(113),1319-1335. Disponível em http://www.scielo.br/pdf/es/v31n113/14.pdf

Chaves, V. L. J. (2010). Expansão da privatização/mercantilização do ensino superior brasileiro: a formação dos oligopólios. Educação e Sociedade,31(111), 481-500. Disponível emhttp://www.scielo.br/pdf/es/v31n111/v31n111a10.pdf

Costa, M. L. F. (2008). Educação a distância no Brasil: perspectiva histórica. In: M. L. F. Costa \& R. M. Zanatta (Orgs.). Educação a Distância no Brasil: aspectos históricos, legais, políticos e metodológicos. Maringá: Eduem.

Costa, M. L. F. (2012). História e políticas públicas para o ensino superior a distância no Brasil: o programa Universidade Aberta do Brasil em questão. HISTEDBR On-line, 12(45), 281-295. Disponível em http://www.histedbr.fae.unicamp.br/revista/edicoes/45/art18 45.pdf

Costa, M. L. F. (2009). O sistema Universidade Aberta do Brasil: democratização e interiorização do ensino superior. In: Costa, M. L. F. (Org.). Introdução à educação a distância. Maringá: Eduem. 
Costa, M. L. F., \& Zanatta, R. M. (2008). Educação a distância no Brasil: programas do ministério da educação. In: M. L. F. Costa \& R. M. Zanatta (Orgs.).Educação a Distância no Brasil: aspectos históricos, legais, políticos e metodológicos. Maringá: Eduem.

Ferreira, J. L. (2008). Moodle: ambiente virtual de aprendizagem. In: M. L. F. Costa \& R. M. Zanatta (Orgs.). Educação a Distância no Brasil: aspectos históricos, legais, políticos e metodológicos. Maringá: Eduem.

IBGE (2011). Censo da educação superior 2010: divulgação dos principais resultados da educação Superior 2010. Brasília, DF: Inep/MEC. Disponível em http://download.inep.gov.br/educacao superior/censo superior/documentos/20 10/divulgacao censo 2010.pdf

Leal, L. N. (2012). Só 11,3\% da população adulta têm faculdade, diz IBGE. Exame. Disponível em http://exame.abril.com.br/brasil/noticias/so-11-3-da-populacaoadulta-tem-faculdade-diz-ibge

Lima, K. R. de S. (2011). A política de ensino superior a distância no Brasil nos anos de neoliberalismo. Perspectiva,29(1), 19-47. Disponível em http://www.periodicos.ufsc.br/index.php/perspectiva/article/viewFile/2175795X.2011v29n1p19/pdfa

Lima, K. R. de S. (2007). Educação a distância ou à distância da educação? Universidade e Sociedade, XVI(39), 81-91.

Malanchen, J. (2007). Políticas de educação a distância: democratização ou canto da sereia? HISTEDBR On-line, 26, 209-216. Disponível em http://gepeto.ced.ufsc.br/politicas-de-educacao-a-distancia-democratizacao-oucanto-da-sereia/

Pereira, L. D. (2009). Mercantilização do ensino superior, educação a distância e Serviço Social. Katálysis, 12(2), 268-277. Disponível em http://www.scielo.br/pdf/rk/v12n2/17.pdf

Santinello, J. (2009). Breve histórico da EaD no Brasil: políticas públicas educacionais e informalidade na educação a distância. In J. Santinello \& M. A. Bronoski. A educação a distância: histórico, ferramentas e contextualizações na Sociedade do Conhecimento. Guarapuava: Unicentro. 
Santos, A. P., \& Cerqueira, E. A. de. (2009). Ensino Superior: trajetória histórica e políticas recentes. InIX Colóquio Internacional sobre Gestão Universitária na América do Sul. Disponível em http://repositorio.ufsc.br/xmlui/handle/123456789/35836

Silva, S. A. da; Silva, S. C. da; Jimenez, S.; \& Segundo, M. das D. M. (2012). Relatório de Pesquisa: educação a distância e precarização do trabalho docente. Revista Eletrônica Arma Crítica, 4, 225-231. Disponível emhttp://www.armadacritica.ufc.br/phocadownload/relatorio 20131.pdf

Vianney, J. (2003). A universidade virtual no Brasil: o ensino superior a distância no país. Tubarão: Unisul. 